\title{
Optimization of Bacterial Poly - $\beta$ - Hydroxy Butyrate (PHB) Production from Different Industrial Waste using Central Composite Design
}

\author{
Veeramanikandan, $\mathrm{V}^{*}$ \\ $P G$ and Research \\ Department of \\ Microbiology \\ MGR College, Hosur, \\ Tamilnadu, India. \\ Pin - 635109
}

\author{
Mrudula, S \\ $P G$ and Research \\ Department of \\ Microbiology \\ MGR College, Hosur, \\ Tamilnadu, India. \\ Pin - 635109
}

\author{
Yuvaraj, $R$ \\ $P G$ and Research \\ Department of \\ Microbiology \\ MGR College, Hosur, \\ Tamilnadu, India. \\ Pin - 635109
}

\author{
Balaji, $P$ * \\ Department of \\ Biotechnology, \\ MGR College, Hosur, \\ Tamilnadu, India. \\ Pin - 635109
}

* Corresponding authors

\begin{abstract}
Poly (ß-hydroxybutyrate) (PHB) belongs to a family of microbial energy/carbon storage compounds collectively known as poly hydroxyalkanoates. About 150 different PHAs have been identified as constituents of bacterial polyesters. PHB is natural, biodegradable polyester which is accumulated in the form of intracellular granules by a variety of heterotrophic and autotrophic aerobic bacteria, photosynthetic anaerobic bacteria, gliding bacteria, Actinomycetes sp, cyanobacteria and recently an anaerobic fatty acid oxidizing gram negative bacterium. Until now there are only few reports on marine PHAs producing microorganisms. With this background an optimization of media components for the effective PHB production using different industrial waste has been attempted for this study.
\end{abstract}

\section{Keywords}

Poly- $\beta$-hydroxy butyrate, PHB, Alcaligenes eutrophus, CCD, RSM, Industrial waste, bacterial polyesters.

\section{INTRODUCTION}

Poly (B-hydroxybutyrate) (PHB) belongs to a family of microbial energy/carbon storage compounds collectively known as poly hydroxyalkanoates. About 150 different PHAs have been identified as constituents of bacterial polyesters [1]. PHB is a natural, biodegradable polyester which is accumulated in the form of intracellular granules by a variety of heterotrophic and autotrophic aerobic bacteria, photosynthetic anaerobic bacteria, gliding bacteria, Actinomycetes sp, cyanobacteria and recently an anaerobic fatty acid oxidizing gram negative bacterium [2]. Until now there are only few reports on marine PHAs producing microorganisms $[3,4]$.

Current worldwide dependence on fossil fuels for plastic manufacture (approximately 270 million metric tones of fossil fuels), the scarcity of space for disposal and growing environmental concerns for non-biodegradable synthetic plastics have fuelled research towards development of ecofriendly biopolymer materials [5,6].considerable emphasis have been laid on the development of five different types of biopolymers which include fibre-reinforced composites, starch based materials, plant produced polymers, microbially produced polymers and biologically based resins, coatings and adhesives[7]. Of these maximum attention has been laid on the development of microbially produced polymer such as Polyhydroxyalkanoates (PHAs).

Despite these decisive benefits, history of research into PHAs has had a slow and chequered history. The composition of PHAs was first described by Lemoigne $[8,9]$ as an unknown material in the form a homopolyseter of 3-hydroxybutyric acids, called PHB synthesized by a soil bacterium - Bacillus. During the following 30 years, interest in this unknown material was negligible. The first report on function of PHB was explained in 1958 by Macrae and Wilkinson[10]. They reported the rapid biodegradability of PHB produced by Bacillus megaterium and Bacillus cereus itself. From here on, the interest in PHB increased dramatically. In the following years, research on PHB and other forms of PHAs included investigations with other microorganisms and potential use of these biopolymers was realized $[11,12,13,14,15]$.

Moreover processing PHB into articles of commerce does not require new investments in technology; existing equipment developed for originally processing polyethylene and polypropylene can be used. However a major draw back to the commercialization of PHB is its higher cost compared with petrochemical-based plastic material[16]. Low cost production of PHB requires improved fermentation and cultivation strategies, inexpensive media [17] and easier downstream processing $[18,19,20]$. Thus using cheap substrates and low cost nutrients at an optimized concentration can feature an improvement in the productivity of PHB at an economical cost.

\section{MATERIALS AND METHODS}

\subsection{Organism}

Alcaligenes eutrophus MTCC1285 was obtained from the Microbial type culture collection, Chandigarh, India. The PHB producing capability of the organism was confirmed by Sudan black staining method[21].

\subsection{Central Composite Design and Response Surface Methodology}

The levels of the significant parameters and interaction effects between four industrial waste and the bacterial strain viz., Alcaligenes eutrophus was used for the production of PHB were analyzed and optimized by using a central composite design in response surface methodology. The experimental design was carried out by using "Stat-Ease Design-Expert" software (version 8.1, Stat-Ease Corporation, USA). The four independent factors were investigated at five different levels 
$(-2,-1,0,+1,+2)$. The response Y (yield of PHB) was analyzed by using a second order polynomial equation in four independent variables and the data were fitted into the equation by multiple regression procedure.

The model equation for analysis is given below Eq

$$
\mathrm{Y}=\beta_{0}+\Sigma \beta_{\mathrm{i}} \mathrm{X}_{\mathrm{i}}+\Sigma \beta_{\mathrm{ii}} \mathrm{X}^{2}{ }_{\mathrm{i}}+\Sigma \beta_{\mathrm{ij}} \mathrm{X}_{\mathrm{i}} \mathrm{X}_{\mathrm{j}}
$$

where $\mathrm{Y}$ is the predicted response, $\mathrm{X}_{\mathrm{i}}, \mathrm{X}_{\mathrm{j}}$ represent the independent variables which influence the response variable $\mathrm{Y}$, and $\beta_{0}, \beta_{\mathrm{i}}, \beta_{\mathrm{ii}}$, and $\beta_{\mathrm{ij}}$ represent the offset term, the ith linear coefficient, the ith quadratic coefficient and the interaction coefficient, respectively. "Design-Expert" 8.1 was used for regression and graphical analyses of the data obtained. Statistical analysis of the model was performed to evaluate the analysis of variance (ANOVA). The student's t-test permitted the checking of the statistical significance of the regression coefficient, and the Fischer's test determined the second-order model equation. The quality of the fit of the polynomial model equation was given by the coefficient of determination (R2). The optimum concentration of the variables were calculated from the data obtained by using the response surface regression procedure of the SAS statistical package (Version 8.1, SAS institute inc. NC. USA).

\subsection{PHB production and extraction}

Four different industrial waste substrates such as (seasame, molasses, sago and paper waste) were collected from industries and were used for the PHB production in different percentage $(10,20,30,40$ and 50\%). The PHB production by A. eutrophus on different industrial wastes [22] under aerobic conditions was studied. A. eutrophus was grown at $37^{\circ} \mathrm{C}$ for $72 \mathrm{~h}$. PHB produced were extracted as described in the method of Ramsay et al.[23, 24].

\subsection{Estimation and qualitative analysis of PHB}

The amount of PHB in the extracted samples was determined spectrophotomertrically at $235 \mathrm{~nm}[25,26]$. The pure form PHB was collected [27] and qualitatively analyzed by infrared method [28] and by NMR method [29].

\section{RESULTS AND DISCUSSION}

\subsection{Central Composite Design and Response Surface Methodology}

Central Composite Design is powerful method for screening significant factor in the presence study, 30 runs were carried out to investigate the production optimization of PHB using four different factors viz., seasame oil waste, sago waste, molasses waste and paper waste. The PHB production varied from 1.7 grams/litre to 3.6 grams/litre in industrial waste used for the study. Response surface methodology help in evaluation of relationship between the dependent (PHB yielded) variable and independent variables and predicted values of the PHB production are shown. The accuracy of the model can be seen by the different between observed and predicted value. The co-efficient and the analysis of variance are presented in table. Fitness of the model was expected by the value of the determination co-efficient in the present PHB comes out to be 2.8 for PHB production high value of adjust co-efficient determination this adjusted 3.6 indicate high significance of model (Fig. 1 and Fig. 6).

\subsection{FTIR spectrum}

Figure 7 shows the FTIR spectrum of the extracted polymer isolated in the study. The FT-IR spectrums obtained were compared with the spectrum of commercially available PHB
The large absorption peak at $3395.07 \mathrm{~cm}^{-1}-3452.34 \mathrm{~cm}^{-1}$ was OH stretching and C-H was between $2924.25 \mathrm{~cm}^{-1}-2994.59$ $\mathrm{cm}^{-1}$. The absorption band at $1723.45 \mathrm{~cm}^{-1}-1728.87 \mathrm{~cm}^{-1}$ attributed to the stretching vibration of the carboxyl bond $(\mathrm{C}=\mathrm{O})$. The band at $2321.87 \mathrm{~cm}^{-1}-2359.02 \mathrm{~cm}^{-1}$ was assigned to the $\mathrm{C} \equiv \mathrm{C}$ stretching of alkynes. Absorption peaks between $1537.95 \mathrm{~cm}^{-1}$ and $1655.59 \mathrm{~cm}^{-1}$ indicates the presence of nitro compounds. The bands between $1547.59 \mathrm{~cm}^{-1}$ and 1597.11 $\mathrm{cm}^{-1}$ arise from $\mathrm{N}-\mathrm{H}$ vibration of amines. Intense bands centered at $1078.01 \mathrm{~cm}^{-1}-1283.39 \mathrm{~cm}^{-1}$ were assigned to C-N vibrations of amine group. The obtained IR absorption peaks correlated with the literature value and with the spectrum of pure PHB. From the above details it is concluded that the compound should be PHB.

\section{6. ${ }^{1} \mathrm{H}$ NMR spectral analysis}

The obtained spectrum for the Alcaligenes eutrophus PHB showed the following results (Figure 8).

The NMR spectra identified the polymer as an isocratic homopolymer. The spectrum revealed the presence of three group of signals characteristic of PHB homopolymer. The doublet at $1.25 \mathrm{ppm}$ was attributed to the methyl group coupled to one proton; the doublet of the quadruplet around $2.5 \mathrm{ppm}$ to the methylene group adjacent to an asymmetric carbon atom bearing a single proton and the singlet at $5.6 \mathrm{ppm}$ to the methyne group. Chloroform-d gave a chemical shift signal at $7.26 \mathrm{ppm}$.

\section{CONCLUSION}

RSM was used to estimate and optimize the PHB production. All the independent variables, quadratic of all the independent variables had highly significant effects on the response values $(\mathrm{p}<0.03)$. The optimal media composition for PHB production was obtained through a central composite design in response surface methodology as 1.7 to 3.6. Under these conditions, the experimental yield of PHB was $3.6 \mathrm{gms}$ in the factor with preliminary media optimization experiments with the use of industrial wastes (Table 1).

\section{REFERENCES}

[1] Steinbuchel, A. and Schlegel, H. L. (1991). Physiology and Molecular genetics of poly (ß-hydroxyalkanoic acid) synthesis in A.eutrophus. Mol.Microbiol. 64; 3437-3443.

[2] Anderson, A. J. and Dawes, E. A. (1990). Occurrence, metabolism, metabolic role and industrial uses of polyhydroxy alkanoates. Microbiol.Rev. 54; 450-472

[3] Sun, W, Cao, J. G, Teng, K. and Meighen, E. A. (1994). Biosynthesis of poly 3-hydroxybutyrate in the luminescent bacterium, Vibrio harveyii and regulation by the lux auto inducer N-(3-hydroxy butanoyl) homoserine lactone. J.Biol.Chem. 269; 20785-20790

[4] Weiner, R. M. (1997). Biopolymers from marine prokaryotes. Trends.Biotechnol. 15; 390-394.

[5] Grengross, T. U. and Slater, S. C. (2000). How green are green plastics? Sci.Am. 8; 37-41.

[6] Thomson, H. (2001). Life in plastic. Engineering. 242 (5); 59-60.

[7] Kolybaba, M. A, Tabil, L. G. and Panigrahi, S. A. (2004). Recent developments in the biopolymer industry. In: Proc, North central ASAE/CSAE Conf. 24-25 Sep, Canada

[8] Lemoigne, M. (1926). Produit de deÂshydratation et de polymeÂrisation de l'acide b-oxybutyrique. Bull.Soc.ChimBiol. 8:770 - 82. 
[9] Lemoigne, M. (1927). Etudes sur l'autolyse microbieÁnne origine de l'acide b-oxybutyrique forme $\hat{\mathrm{A}}$ par autolyse. Ann.Inst.Pasteur. 41: 148 - 65.

[10] Macrae, R, M. and Wilkinson, J, F. (1958). Poly B Hydroxybutyrate metabolism in washed suspension of Bacillus megaterium. J.Gen.Microbiol. 19; 210-222

[11] Volova, T. (2004). Polyhydroxy alkanoates: Plastic material of the $21^{\text {st }}$ century. Chapter 6: Application of PHAs, New York, USA: Nova Scientific publishers Inc: p 205-21

[12] Scott, G. (2005). Biodegradable plastics in agriculture. In: Smith R, Editor. Biodegradable polymers for industrial applications. Cambridge, England: CRC Press; p 451-473

[13] Noda, I, Green, P. R, Satkowski, M. M. and Schectmann, L. A. (2005). Preparation and properties of a novel class of polyhydroxy alkanoate copolymers. Biomacromolecules. 6; 580-586.

[14] Pandey, J. K, Kumar, A. P, Mishra, A. K, Drzal, L. T. and Singh, R. P. (2005). Recent advances in biodegradable nanocomposites. J.nanosci.nanotechnol. 5; 497-526

[15] Ren, Q, Grubelnik, A, Hoerler, M, Ruth, K, Hartmann, K, Felber, H. (2005). Bacterial poly (hydroxyalkanoates) as a source of chiral hydroxy alkanoic acids. Biomacromolecules. 6; 2290-8.

[16] Chisti, Y. and Grothe, E. (2000). Poly (ß hydroxy butyric acid) thermoplastic production by Alcaligenes latus: Behaviour of fed-batch cultures. Bioprocess.Engineering. $22 ; 441-449$

[17] Arun, A., Murrugappan, Rm, David Ravindran, A. D, Veeramanikandan V. and Shanmuga Balaji. (2006). Utilization of various industrial wastes for the production of poly-ß-hydroxy butyrate (PHB) by Alcaligenes eutrophus. African.Journal.of.Biotechnology. Vol. 5 (17), pp. $1524-1527$

[18] Chisti, Y. (1998). Strategies in downstream processing. In: Subramanian G. (ed); Bioseparation and Bioprocessing. A Handbook, Vol. 2, Wiley-VCH, New York, pp 3-30.
[19] Tamer, I. M, Moo-Young, M. and Chisti, Y. (1998a). Disruption of Alcaligenes latus for recovery of poly ( $\beta$ hydroxy butyric acid): comparison of high-pressure homogenization, bead milling, and chemically induced lysis. Ind.Eng.Chem.Research. 37; 1807-1814.

[20] Tamer, I, M, Moo-Young, M. and Chisti, Y. (1998b). Optimisation of poly (B-hydroxybutyric acid) recovery from Alcaligenes latus: combined mechanical and chemical treatments. Bioprocess Engg. 19; 459-468.

[21] Kitamura S, Doi Y (1994). Staining method of poly (3hydroxyalkanotes acids) producing bacterial by nile blue. Biotechnol. Techniques 8:345-350

[22] Lee SY, Choi J (1999). Polyhydroxyalkanoate: biodegradable polymer. In Manual of Industrial Microbiology and Biotechnology, 2 edn. Edited by Demain AL., Deavies JE, Washington DC:ASM:616627.

[23] Ramsay, J. A, Berger, E, Ramsay, B. A. and Chavarie, C. (1994a). Recovery of poly-3-hydeoxyalkanoic acid granules by a surfactant - hypochlorite treatment. Biotechnol.Techning 9(10); 709-712.

[24] Ramsay, Berger, E, Chaverie, C. and Ramsay, B. A. (1994b). Extraction of poly- 3-hydroxybutyrate using chlorinated solvents. Biotechnol.Techniques 8:589-594.

[25] Lee IY, Chang HN, Park YH (1995). A simple method for recovery of microbial poly - $\beta$ - hydroxybutrate by alkaline solution treatment.J.Microbial.Biotechnol.5:238240

[26] Law, Ralph, A. Slepecky (1960). Asay of poly bhydroxyl butyric acid. J.Bacterioloty. 82:33-36.

[27] Lee, S. Y., 1996, Bacterial Polyhydroxyalkanoates. Biotechnology and Bioengineering, $49: 1-14$.

[28] Silverstein, Bassler, Morril (1981). Spectrometric identification of organic compounds. John wiley and Sons 4th Edn.

[29] Bernard N, KM Sandrs (1989). The poly Hydroxy butyrate granules in vivo. J. Biol. Chem. 264:3286-3292 
Figure 1. - PHB Model Graph of Alcaligenes eutrophus in Sago and seasame oil waste

Design-Expert@ Software

Factor Coding: Actual

PHB Production

- Design points above predicted value

3.6

$\mathrm{X} 1=\mathrm{A}:$ Sago wast

X2 = B: Seasame Oil

Actual Factors

C: Molasses $=0.00$

D: Paper Waste $=0.00$

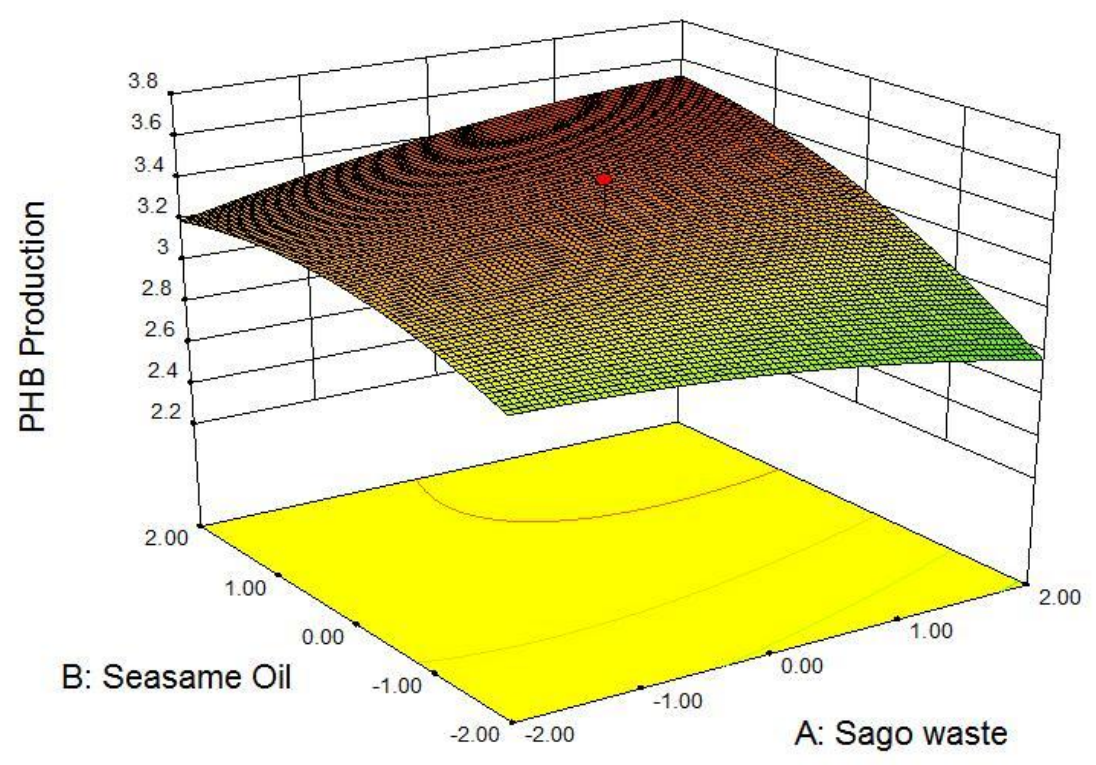

Figure 2. - PHB Model Graph of Alcaligenes eutrophus in Sago and molasses waste

Design-Expert( Softwar

PHB Production

- Design points above predicted value

3.6

1.7

$\mathrm{X} 1=\mathrm{A}$ : Sago waste

Actual Factors

D.: Seasame Oil $=0.00$

D. Paper Waste $=0.00$

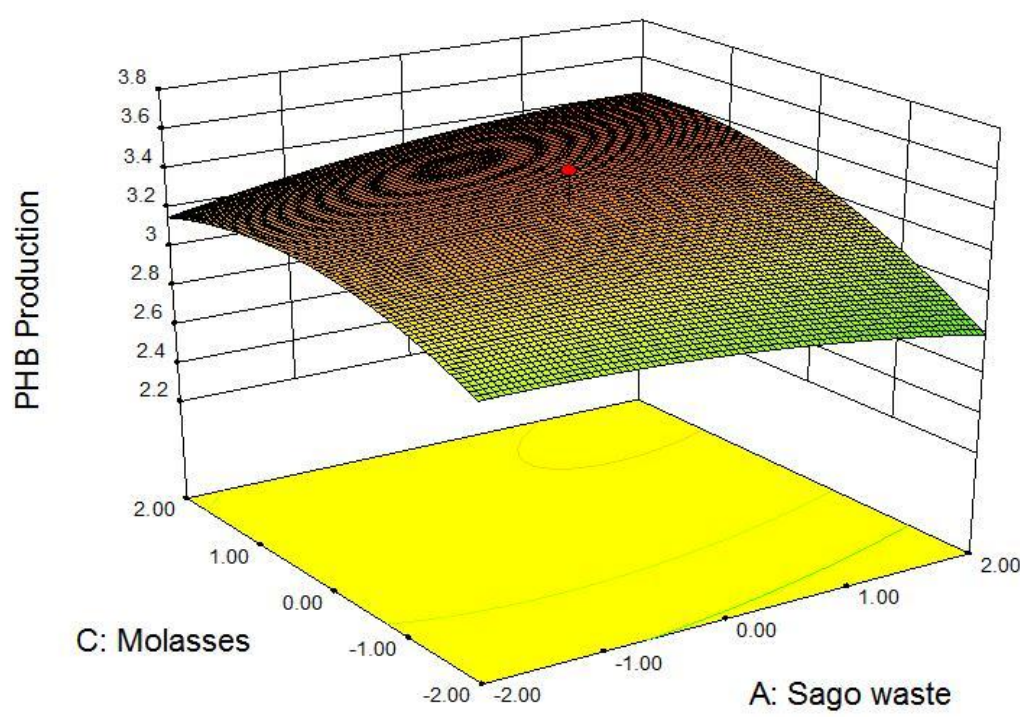


Figure 3. PHB Model Graph of Alcaligenes eutrophus in Sago and paper waste

Design-Expert( Software

Factor Coding: Actual

PHB Production

- Design points above predicted value

$\prod_{1.7}^{3.6}$

$\mathrm{X} 1=\mathrm{A}:$ Sago waste

X2 = D: Paper Waste

Actual Factors

B: Seasame Oil $=0.00$

C: Molasses $=0.00$

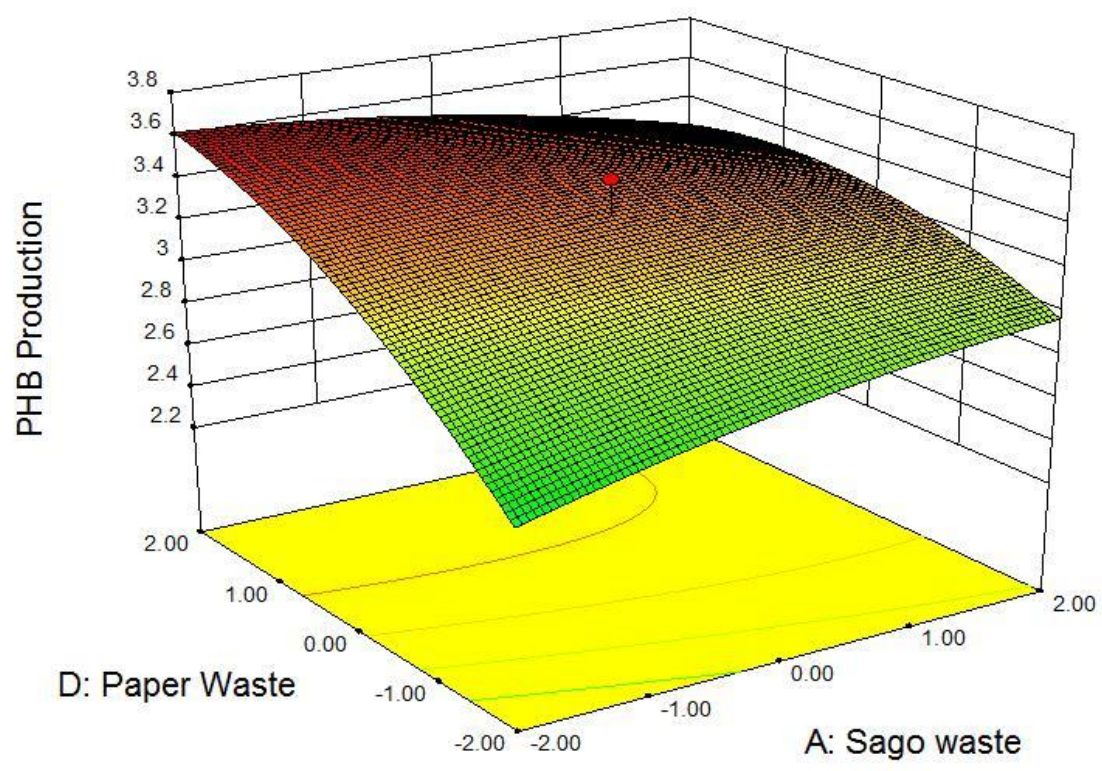

Figure 4. PHB Model Graph of Alcaligenes eutrophus in Seasame oil and molasses waste

Design-Expert( Software

Factor Coding: Actual

- Design points above predicted value

$\prod_{1.7}^{3.6}$

$\mathrm{X} 1=\mathrm{B}$ : Seasame Oil

$\mathrm{X} 2=\mathrm{C}:$ Molasses

Actual Factors

A: Sago waste $=0.00$

D: Paper Waste $=0.00$

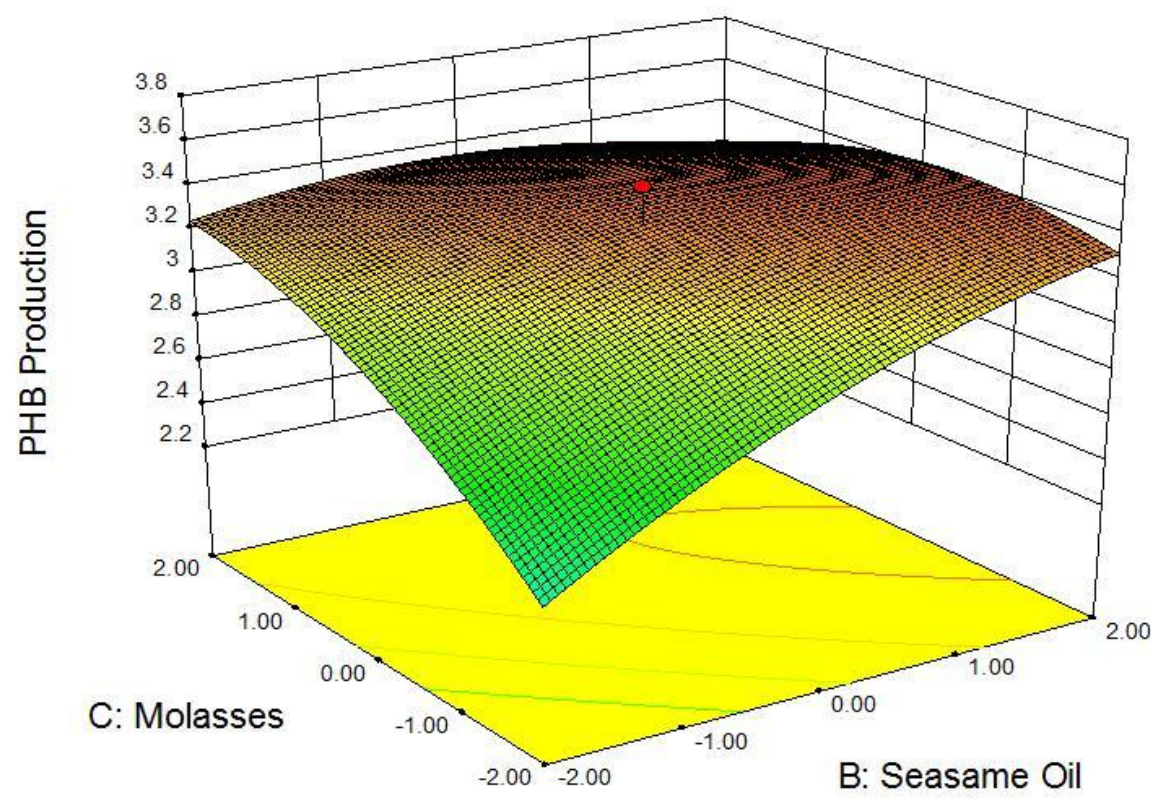


Figure 5. PHB Model Graph of Alcaligenes eutrophus in Seasame oil and paper waste

Design-Expert( Software

Factor Coding: Actual

PHB Production

- Design points above predicted value

$\prod_{1.7}^{3.6}$

$\mathrm{X} 1=\mathrm{B}:$ Seasame Oil

X2 = D: Paper Waste

Actual Factors

A: Sago waste $=0.00$
C. Molasses $=0.00$

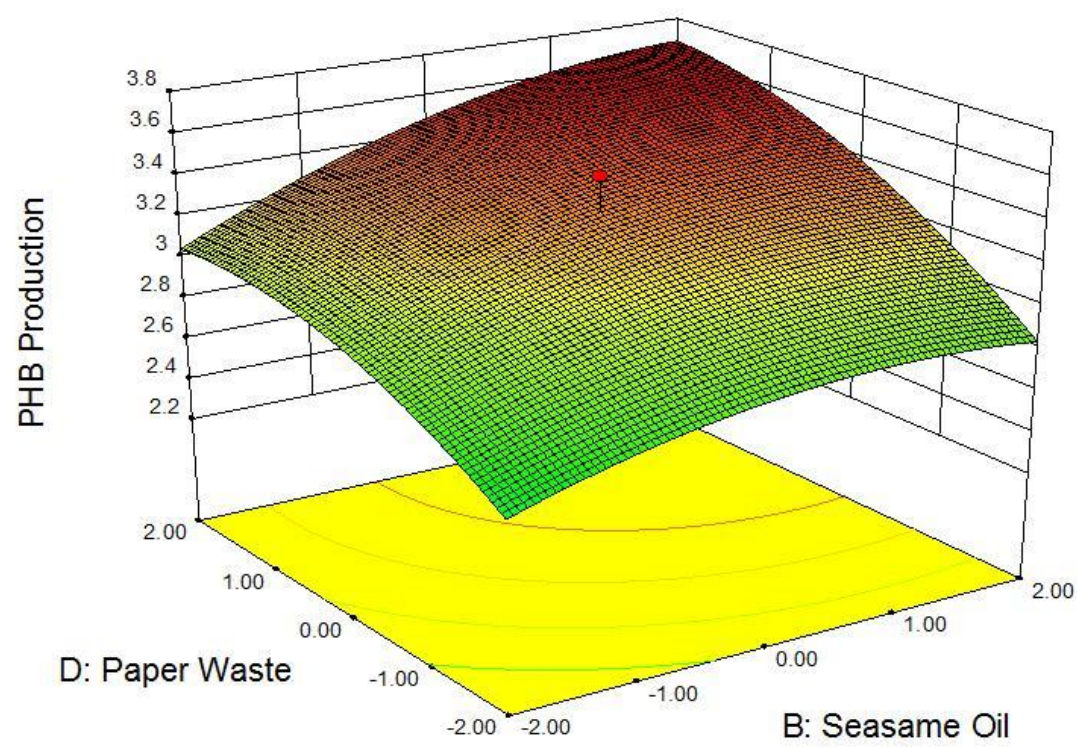

Figure 6. PHB Model Graph of Alcaligenes eutrophus in Molasses and paper waste

Design-Expert( Software

Factor Coding: Actual

- Design points above predicted value

$\prod_{1.7}^{3.6}$

$\mathrm{X} 1=\mathrm{C}$ : Molasses

X2 = D: Paper Waste

Actual Factors

A: Sago waste $=0.00$

B: Seasame Oil $=0.00$

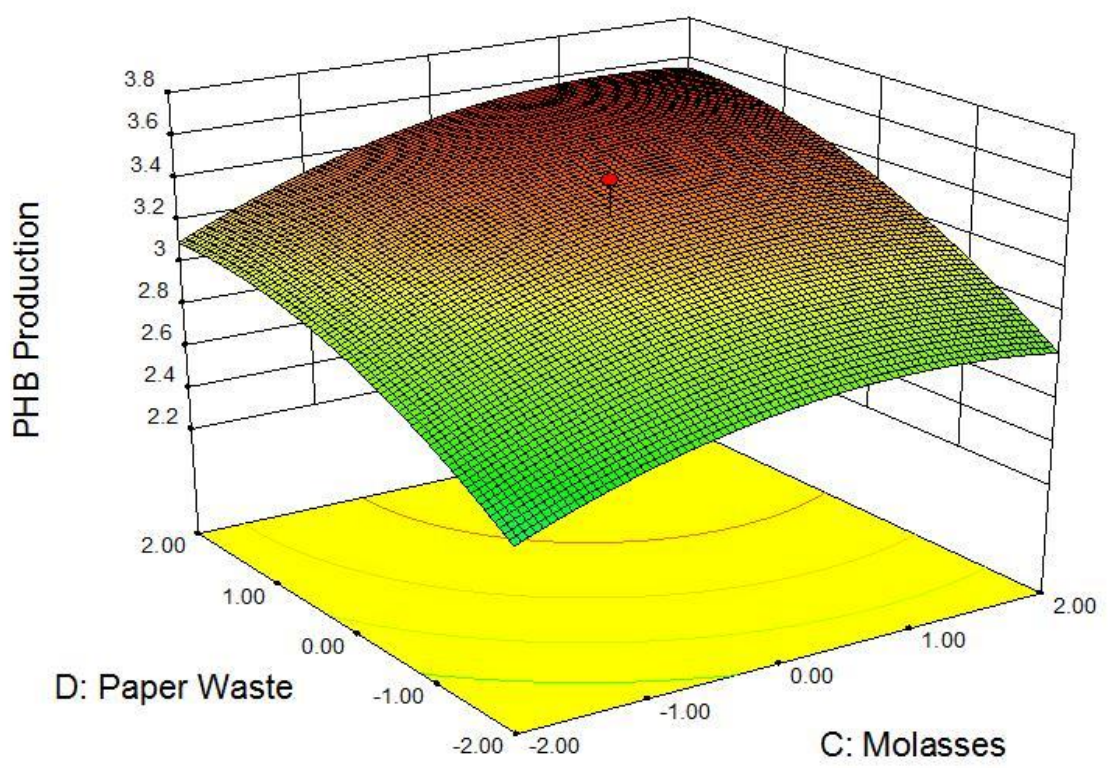


Figure 7. FTIR Spectrum of PHB produced by Alcaligenes eutrophus

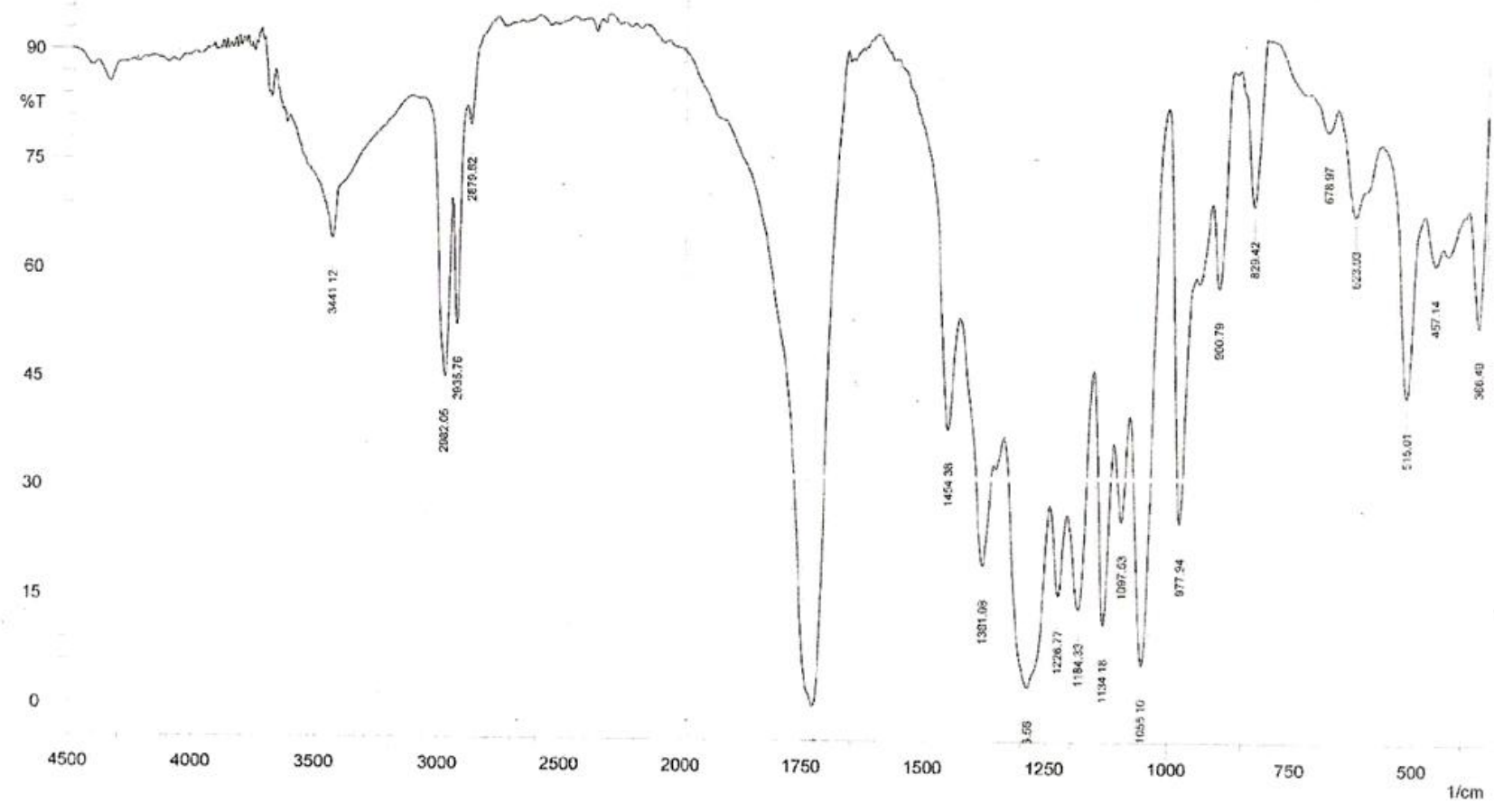

Figure 8. ${ }^{1}$ H NMR Spectrum of PHB produced by Alcaligenes eutrophus

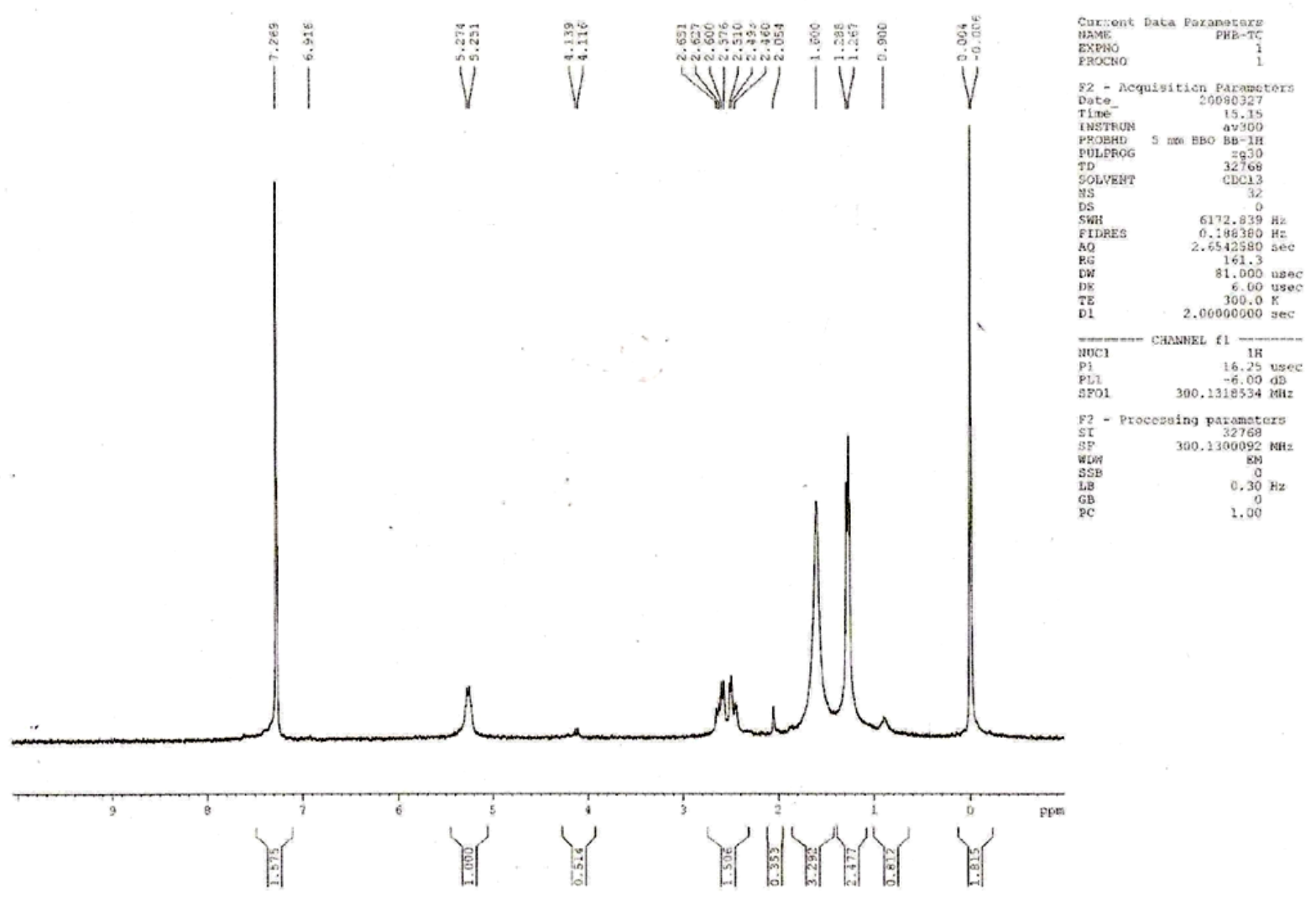


Table 1. Response surface methodology yield of PHB by Alcaligenes eutrophus

\begin{tabular}{|c|c|c|c|c|c|}
\hline Run & $\begin{array}{c}\text { Factor } 1 \\
\text { A:Sago waste } \\
\text { Grams (g) } \\
\end{array}$ & $\begin{array}{c}\text { Factor } 2 \\
\text { B:Seasame Oil } \\
\text { Grams (g) }\end{array}$ & $\begin{array}{c}\text { Factor } 3 \\
\text { C:Molasses } \\
\text { Grams (g) }\end{array}$ & $\begin{array}{c}\text { Factor } 4 \\
\text { D:Paper Waste } \\
\text { Grams (g) }\end{array}$ & $\begin{array}{c}\text { Response 1 } \\
\text { PHB production } \\
\text { g/litre } \\
\end{array}$ \\
\hline 1 & 0.00 & -4.00 & 0.00 & 0.00 & 2.5 \\
\hline 2 & -4.00 & 0.00 & 0.00 & 0.00 & 3.5 \\
\hline 3 & -2.00 & -2.00 & 2.00 & 2.00 & 3.1 \\
\hline 4 & 4.00 & 0.00 & 0.00 & 0.00 & 3.1 \\
\hline 5 & 2.00 & 2.00 & -2.00 & 2.00 & 3.5 \\
\hline 6 & -2.00 & 2.00 & 2.00 & 2.00 & 3.5 \\
\hline 7 & -2.00 & 2.00 & -2.00 & 2.00 & 3.5 \\
\hline 8 & 0.00 & 0.00 & -4.00 & 0.00 & 2.5 \\
\hline 9 & 0.00 & 0.00 & 0.00 & -4.00 & 2.5 \\
\hline 10 & 2.00 & -2.00 & 2.00 & 2.00 & 3.6 \\
\hline 11 & 2.00 & 2.00 & -2.00 & -2.00 & 2.9 \\
\hline 12 & 0.00 & 0.00 & 0.00 & 0.00 & 3.5 \\
\hline 13 & 0.00 & 0.00 & 0.00 & 0.00 & 3.5 \\
\hline 14 & 0.00 & 0.00 & 0.00 & 0.00 & 3.5 \\
\hline 15 & -2.00 & -2.00 & 2.00 & -2.00 & 2.45 \\
\hline 16 & -2.00 & -2.00 & -2.00 & 2.00 & 2.75 \\
\hline 17 & 0.00 & 0.00 & 0.00 & 0.00 & 3.1 \\
\hline 18 & 2.00 & 2.00 & 2.00 & -2.00 & 3 \\
\hline 19 & 0.00 & 0.00 & 0.00 & 0.00 & 3.1 \\
\hline 20 & 2.00 & -2.00 & 2.00 & -2.00 & 2.6 \\
\hline 21 & 0.00 & 0.00 & 0.00 & 4.00 & 3.3 \\
\hline 22 & 2.00 & 2.00 & 2.00 & 2.00 & 3.1 \\
\hline 23 & 0.00 & 4.00 & 0.00 & 0.00 & 3.5 \\
\hline 24 & 2.00 & -2.00 & -2.00 & -2.00 & 1.7 \\
\hline 25 & 2.00 & -2.00 & -2.00 & -2.00 & 1.7 \\
\hline 26 & 0.00 & 0.00 & 0.00 & 0.00 & 3.1 \\
\hline 27 & -2.00 & 2.00 & 2.00 & -2.00 & 1.8 \\
\hline 28 & -2.00 & -2.00 & -2.00 & -2.00 & 1.96 \\
\hline 29 & -2.00 & 2.00 & -2.00 & -2.00 & 1.98 \\
\hline 30 & 0.00 & 0.00 & 4.00 & 0.00 & 3.2 \\
\hline
\end{tabular}

